\title{
ROLE OF CFTR IN LYSOSOME ACIDIFICATION
}

Rebecca W. Van Dyke, Karen V. Root, James H. Schreiber and James M. Wilson

Department of Medicine and Cystic Fibrosis Center

University of Michigan, Ann Arbor, MI

Received March 2, 1992

SUMMARY: The role of CFTR in lysosome acidification was examined in CFPAC-1 pancreatic adenocarcinoma cells with the $\triangle F 508$ mutation that were transduced with a retroviral vector (PLJ-CFPAC) or with the normal CFTR gene (CFTR-CFPAC). Steadystate lysosomal $\mathrm{pH}$ in intact cells was lower in PLJ-CFPAC cells than CFTR-CFPAC cells (3.55 vs 3.80 ) and was not affected by cAMP or forskolin. Initial rates of ATPdependent acidification of isolated lysosomes and steady-state ATP-dependent $\mathrm{pH}_{\mathrm{i}}$ were similar in both cell lines over a range of chloride concentrations and were not altered when cells were exposed to cAMP or to forskolin prior to preparation of lysosomes. These observations suggest that CFTR plays no role in acidification of lysosomes, possibly due to limited permeability of lysosomal membranes to chloride. C 1992 Academic Press. Inc.

A defect in CAMP-stimulated chloride transport appears to underlie many of the clinical features in cystic fibrosis and the defective gene, cystic fibrosis transmembrane conductance regulator (CFTR), appears to function predominantly either as a chloride channel regulator or a chloride channel (1-3). Although defective chloride transport across plasma membranes of epithelial cells has been well documented in cystic fibrosis, little is known regarding chloride transport across intracellular membranes. Endosomes, lysosomes and some Golgi vesicles contain an electrogenic proton pump ( $\mathrm{H}^{+}$-ATPase) that, in most of these vesicles, works in parallel with a chloride conductance to maximally acidify vesicie interiors $(4,5)$. To determine whether CFTR alters organellar acidification, we investigated the effects of CAMP and forskolin on acidification of lysosomes in pancreatic cell lines that contain the defective ( $\triangle F 508)$ CFTR or have been successfully complemented with the normal CFTR gene.

\section{MATERIALS AND METHODS}

Cell culture: CFPAC-1 cells, derived from a pancreatic adenocarcinoma in a patient with cystic fibrosis (6), transduced with retroviral vectors without (PLJ) or with (PLJCFTR) the normal CFTR gene (7) were used. The CFTR-transduced cells exhibited cAMP-stimulation of anion fluxes (7) and of chloride-induced quenching of the chloride-sensitive fluorescent dye 6-methoxy-N-[3-sulfopropyl] quinolinium (R.W. Van Dyke, unpublished observations). Cells were grown to confluence in modified Eagle's medium with $10 \%$ fetal bovine serum, $1 \%$ penicillin-streptomycin and $5 \% \mathrm{CO}_{2}$ at $37^{\circ} \mathrm{C}$ 
on $10 \mathrm{~cm}$ plastic dishes or collagen-coated $25 \mathrm{~mm}$ glass coverslips. Eighteen hours prior to use, $2.5 \mathrm{mg} / \mathrm{ml} \mathrm{70,000} \mathrm{mw} \mathrm{fluorescein} \mathrm{isothiocyanate-dextran} \mathrm{(FITC-dextran)}$ was added to the culture medium. Two hours prior to use, culture medium was removed, cells washed three times with warm phosphate-buffered saline and fresh culture medium replaced for a final two hour incubation at $37^{\circ} \mathrm{C}$.

Lysosome pHi in intact cells: FITC-dextran loaded cells were mounted in a temperature-controlled perfusion chamber on the stage of a fluorescent Nikon microscope coupled to a dual wavelength spectrofluorometer (SPEX Industries) and were perfused at $37^{\circ} \mathrm{C}$ with buffer $\left(120 \mathrm{mM} \mathrm{NaCl}, 2.5 \mathrm{mM} \mathrm{K} 2 \mathrm{HPO}_{4}, 1 \mathrm{mM} \mathrm{CaSO} 4,0.1\right.$ $\mathrm{mM} \mathrm{MgSO} 4,10 \mathrm{mM} \mathrm{N}$ - [2-Hydroxyethyl] piperazine-N'- [2-ethanesulfonic acid] (HEPES), $10 \mathrm{mM}$ glucose, $\mathrm{pH} 7.35$ ) without or with $10 \mu \mathrm{M}$ forskolin and $100 \mu \mathrm{M}$ dibutyryl CAMP. Fluorescence of lysosomes from groups of 10-15 cells was assessed at two excitation wavelengths (493 nm, pH-sensitive and $450 \mathrm{~nm}, \mathrm{pH}$-insensitive) and emission wavelength $530 \mathrm{~nm}$. Lysosome $\mathrm{pH}_{i}$ was calculated from a standard curve of the ratio of fluorescein fluorescence at the two excitation wave lengths to $\mathrm{pH}$ during perfusion with high potassium buffers $(100 \mathrm{mM} \mathrm{KCl}, 40 \mathrm{mM} \mathrm{HEPES}, 40 \mathrm{mM}$ 2-[NMorpholino] ethanesulfonic acid (MES), $\mathrm{pH} \sim 3.5,4.5,5.5,6.25)$ containing $15 \mu \mathrm{M}$ nigericin, $50 \mathrm{mM}$ 2-deoxy-glucose and $5 \mathrm{mM} \mathrm{Na}$ azide (8).

Lysosome isolation: 10 minutes before use, saline solvent, $0.5 \mathrm{mM}$ dibutyryl cAMP or $10 \mu \mathrm{M}$ forskolin was added to culture medium. Subsequently culture plates were chilled, medium was replaced by cold buffer $(250 \mathrm{mM}$ sucrose, $3 \mathrm{mM}$ imidazole, $\mathrm{pH}$ 7.0) and cells were gently scraped. Buffer and cells were saved and culture dishes were rinsed and scraped twice more. Cells were centrifuged at $750 \mathrm{~g}$ for 6 minutes, supernatents were removed and cell pellets were resuspended in $3.5 \mathrm{ml}$ lysis buffer (250 mM sucrose, $10 \mathrm{mM}$ 3-[N- Morpholino] propanesulfonic acid (MOPS)/Tris [hydroxymethyl] aminomethane (TRIS), $1 \mathrm{mM}$ Na2EDTA, pH 7.6) on ice. The cell suspension was pipetted up and down 12 times. Unbroken cells were pelleted, supernatent was saved and the cell pellet relysed twice more. Supernatents were combined and unbroken cells and nuclei were pelleted at $1300 \mathrm{~g}$ for 12 minutes. Supernatents were centrifuged at $15,000 \mathrm{gav}$ for 15 minutes. Pelleted vesicles were resuspended in a small volume of isotonic buffer $(140 \mathrm{mM} \mathrm{Kgluconate,} 10 \mathrm{mM}$ bis [2Hydroxyethyl] imino-tris [hydroxymethyl] methane (Bis-Tris), pH 7.0 or $140 \mathrm{mM} \mathrm{N}$ methyl-D-glucamine (NMDG) gluconate, $10 \mathrm{mM}$ Bis-Tris, $\mathrm{pH} \mathrm{7.0)}$ and kept on ice until used.

Acidification of isolated lysosomes: Isolated vesicles $(55-175 \mu \mathrm{g})$ were suspended in $2 \mathrm{ml}$ of buffer ( $140 \mathrm{mMK}$ salts or $140 \mathrm{mM} \mathrm{NMDG}$ salts, $10 \mathrm{mM}$ Bis-Tris, $\mathrm{pH} \mathrm{7.0)} \mathrm{in} \mathrm{a}$ well stirred cuvette in a dual wavelength spectrofluorometer at $22^{\circ} \mathrm{C}$ and lysosome $\mathrm{pH}$ was calculated from the ratio of fluorescein fluorescence at two excitation wavelengths and a standard curve obtained at the end of each assay by addition of aliquots of acid in the presence of $2 \mu \mathrm{M}$ monensin and $0.4 \mu \mathrm{M}$ carbonyl cyanide m-chlorophenylhydrazone (CCCP) $(9,10)$. Initial rates of acidification and steady-state ATP.

dependent $\mathrm{pH}$ i were determined after addition of $5 \mathrm{mM}$ MgATP. Buffer contained lgGantifluorescein antibody to quench extralysosomal fluorescence. All assays were run in duplicate in each preparation of vesicles.

Statistics: Results are expressed as mean \pm SEM $(n \geq 3)$ of assays in " $n$ " different preparations of vesicles. Differences between control and experimental assays were examined with paired $t$ tests.

\section{RESULTS}

Cells exposed to FITC-dextran for 16 hours followed by a 2 hour chase period exhibited many brightly fluorescent cytoplasmic spots, many of them clustered around the nucleus. Lysosome $\mathrm{pH}_{j}$ in intact cells under control conditions was more acidic in the PLJ-CFPAC (cystic fibrosis) cells $\left(\mathrm{pH}_{i}, 3.55 ;\left[\mathrm{H}^{+}\right]\right.$, $\left.2.84 \pm 1.22 \times 10^{-4} \mathrm{M}\right)$ than in the CFTR-CFPAC (corrected) cells $\left(\mathrm{pH}_{i}, 3.80 ;\left[\mathrm{H}^{+} \mathrm{i}\right], 1.57 \pm 0.49 \times 10^{-4} \mathrm{M}\right)$ (Figure 1). 


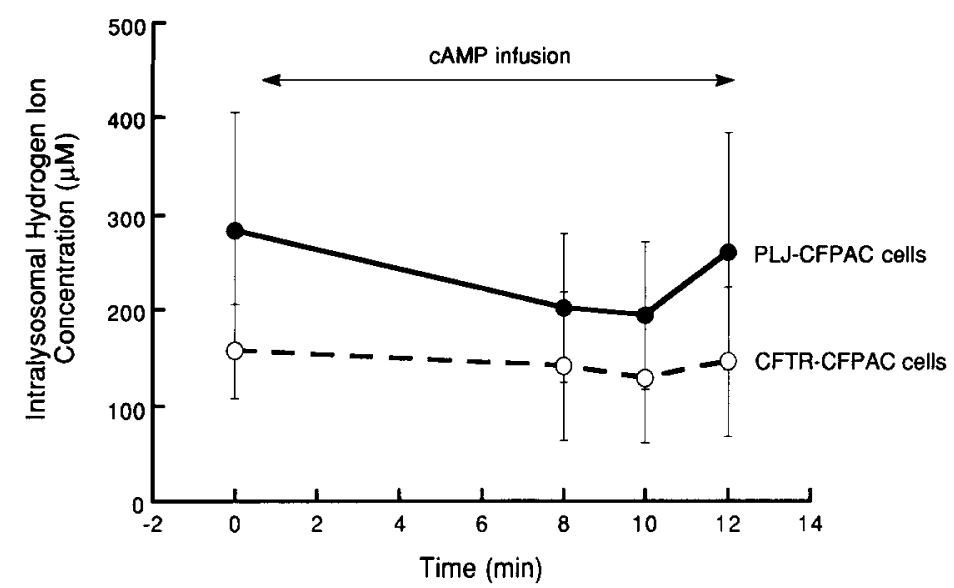

Figure 1. Intralysosomal hydrogen ion concentration measured in intact cells under control conditions (time 0 ) and during perfusion with medium containing $100 \mu \mathrm{M}$ dibutyryl cAMP and $10 \mu \mathrm{M}$ forskolin (arrow). PLJ-CFPAC cells, closed circles; CFTR-CFPAC cells, open circles. Symbols are the mean \pm SEM of measurements from 6-14 different coverslips.

Superfusion of the cells with $10 \mu \mathrm{M}$ forskolin and $100 \mu \mathrm{M}$ dibutyryl cAMP caused no significant change in lysosomal $\left[\mathrm{H}^{+} \mathrm{i}\right]$ in either cell line (Figure 1 ).

Lysosomes released from disrupted cells were enriched by differential centrifugation. Although the final vesicle pellet was not pure, the load/chase technique employed assures that all fluorescein was in lysosomes $(8,10,11)$. Lysosomes were incubated in ion-containing medium until pre-established $\mathrm{pH}$ gradients had dissipated prior to measuring initial rates of ATP-dependent acidification and steady-state ATPdependent $\mathrm{pH}_{i}$. As shown in figure 2, initial rates ranged from $0.68-1.24 \mathrm{pH}$ units/minute and were not significantly affected by medium chloride concentration, presence or absence of the normal CFTR gene or prior treatment with $0.5 \mathrm{mM}$ dibutyryl
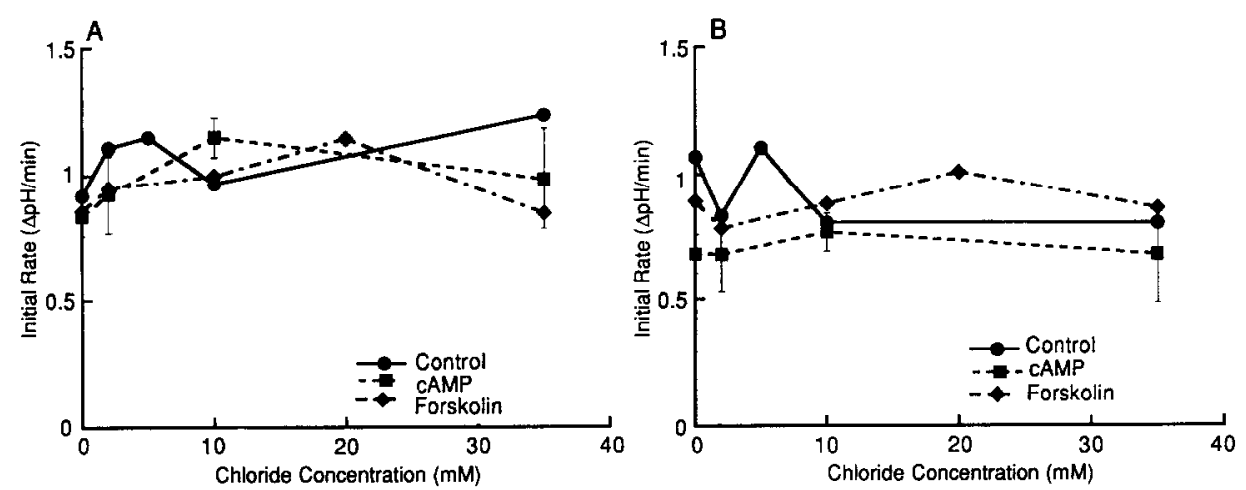

Figure 2. Initial rates of ATP-dependent acidification of lysosomes isolated from PLJ-CFPAC cells (A) or CFTR-CFPAC cells (B) under control conditions (circles) or after 10 minute exposure to $0.5 \mathrm{mM}$ dibutyryl-cAMP (squares) or 10 $\mu \mathrm{M}$ forskolin (diamonds). Lysosomes were assayed in media containing the indicated concentrations of $\mathrm{Cl}^{-}$with gluconate as the counter anion. Points represent the mean ( \pm SEM for $n \geq 3$ ) of results from duplicate assays in 1-3 different preparations of lysosomes. 

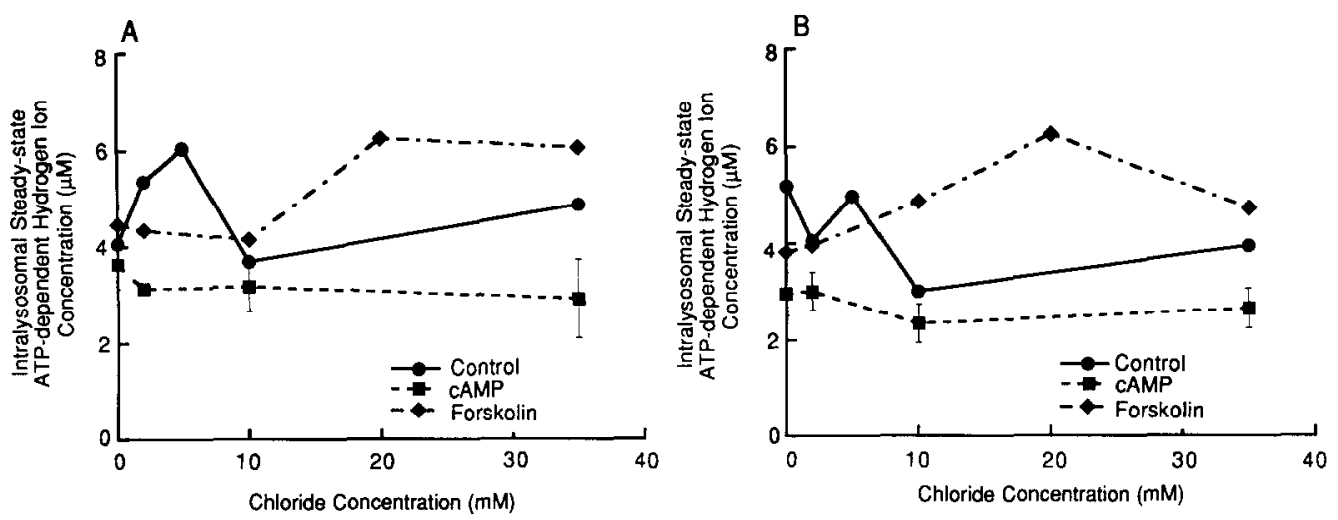

Eigure 3. Steady-state ATP-dependent intralysosomal hydrogen ion concentration in lysosomes isolated from PLJ-CFPAC cells (A) or CFTR-CFPAC cells (B) under control conditions (circles) or after pre-treatment of cells with $0.5 \mathrm{mM}$ dibutyryl cAMP (squares) or $10 \mu \mathrm{M}$ forskolin (diamonds). Symbols represent mean $( \pm$ SEM for $n \geq 3$ ) of duplicate assays on 1-3 different preparations of lysosomes.

cAMP or $10 \mu \mathrm{M}$ forskolin. Similarly, steady-state ATP-dependent intralysosomal hydrogen ion concentrations ranged from 2.74 to $6.25 \times 10^{-6} \mathrm{M}$ and were not significantly affected by medium chloride, presence of normal CFTR or pretreatment with $0.5 \mathrm{mM}$ dibutyryl cAMP or $10 \mu \mathrm{M}$ forskolin (Figure 3).

Since most endocytic vesicles appear to exhibit chloride, and perhaps potassium, conductances which stimulate vesicle acidification by $200-300 \%(9,12,13)$ by minimizing the vesicle interior-positive membrane potential generated by the electrogenic $\mathrm{H}^{+}$- ATPase, further studies were performed to look at the effects of chloride and potassium on acidification of lysosomes from PLJ-CFPAC cells. When lysosomes (Fig. 4) were suspended initially in isotonic medium containing large,

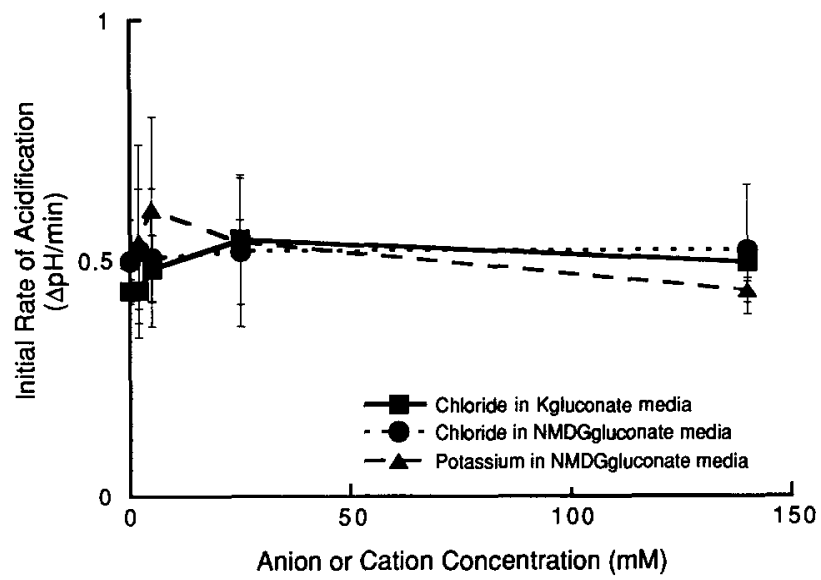

Figure 4. Effects of chloride or potassium on initital rates of ATP-dependent acidification of lysosomes prepared from PLJ-CFPAC cells. Lysosomes were prepared in Kgluconate (squares) or NMDGgluconate (circle, triangles) media and were assayed in media in which chloride replaced gluconate (squares, circles) or potassium replaced NMDG (triangles). Symbols represent the mean \pm SEM of results from three separate preparations of lysosomes. 
poorly permeable cations ( $\mathrm{N}$-methyl-d-glucamine; $\mathrm{NMDG}^{+}$) and anions (gluconate), replacement of either $\mathrm{NMDG}^{+}$with $\mathrm{K}^{+}$or gluconate with $\mathrm{Cl}^{-}$had little effect on initial rates of ATP-dependent acidification. Similarly, when lysosomes were suspended initially in isotonic Kgluconate medium, replacement of gluconate by $\mathrm{Cl}^{-}$had little effect.

\section{DISCUSSION}

The present studies show that the presence of the normal CFTR gene has little effect on either initial rates of acidification or steady-state $\mathrm{pH}_{\mathrm{j}}$ of lysosomes in CFPAC1 cells. These cells were selected for study as they are epithelial cells from pancreatic ductular tissue, a tissue substantially affected by cystic fibrosis. CFPAC-1 cells are homozygous for the $\triangle F 508$ mutation in the CFTR gene, the most common genotype for cystic fibrosis. Clones of transduced CFPAC- 1 cells that express the normal CFTR gene (CFTR-CFPAC) also exhibit CAMP-stimulated efflux of 125 I whereas clones of CFPAC-1 cells transduced with the retroviral vector alone (PLJ - CFTR) that express only the endogenous $\triangle F 508$ CFTR. CFTR also appears to modulate cytoplasmic pH in these cells (14). Thus these cells seemed ideal tools for testing a role for CFTR in regulating acidification of intracellular organelles.

The studies outlined here, however, failed to show any effect of CFTR on lysosome acidification, either in the intact cell or in isolated lysosomes. Similarly, neither chloride exposure nor treatment of intact cells with cAMP or forskolin affected lysosome acidification. These results suggest that either functional CFTR is not present in lysosome membranes or it does not play a role in determining lysosome proton transport.

Since the proton pump that acidifies lysosomes, endosomes and other intracellular organelles is electrogenic, the lack of effect of chloride or potassium on CFPAC Iysosome acidification suggests that these lysosomes exhibit little if any chloride or potassium conductance, a finding that is in contrast to most endocytic vesicles $(9,12,13,15)$ including rat liver lysosomes $(10)$. Lysosome transporters for sugars (16) and anions such as sulfate (17) and phosphate (18) have been identified and it is possible that uptake of some of these anions facilitates acidification of CFPAC-1 lysosomes by minimizing the membrane potential and maximizing the proton chemical gradient $(\Delta \mathrm{pH})$ in a manner analogous to that of chloride in endocytic vesicles.

These negative results are consistent with those recently reported by Barasch and colleagues (19) who reported that the $\mathrm{pH}_{i}$ of lysosomes (measured with an immunoelectronmicroscopic technique) in nasal epithelial cells from patients with cystic fibrosis did not differ from normal controls. Overall our studies suggest that lysosomal acidification is normal in cystic fibrosis and that neither CFTR nor any other chloride conductance plays an important role in acidification of pancreatic lysosomes. 
ACKNOWLEDGMENTS: This work was supported by grants from the National Institutes of Health (NIDDK grant DK-38333 to Rebecca Van Dyke) and the Cystic Fibrosis Foundation (Cystic Fibrosis Center Grant, J. Wilson, Co-Director and Pilot/Feasibility Project to R. Van Dyke). The authors would like to thank Loretha Ervin for technical assistance and Cheryl Swanigan for manuscript preparation.

\section{REFERENCES}

1. Rommens, J.M., Dho, S., Bear C.E., Kartner, N., Kennedy, D., Riordan, J.R., Tsui, L-C. and Foskett, J.K. (1991) Proc. Natl. Acad. Sci. USA, 88, 7500-7504.

2. Kartner, N., Hanrahan, J.W., Jensen, T.J., Naismith, A.L., Sun, S., Ackerley, C.A., Reyes, E.F., Tsui, L.-C., Rommens, J.M., Bear, C.E. and Riordan, J.R. (1991) Cell, 64, 681-691.

3. Anderson, M.P., Rich, D.P., Gregory, R.J., Smith, A.E., Welsh, M.J. (1991) Science, 251, 679-682.

4. Van Dyke, R.W. (1990) J. Int. Med., 228. Suppl. 1, 41-46.

5. Forgac, M. (1989) Physiol. Reviews, 69, 765-796.

6. Schoumacher, R.A., Ram, J., lannuzzi, M.C., Bradbury, N.A., Wallace, R.W., Hon, C.T., Kelly, D.R., Schmid, S.M., Gelder, F.B., Rado, T.A., Frizzell, R.A. (1990) Proc. Natl. Acad. Sci. USA, 87, 4012-4016.

7. Drumm, M.T., Pope, H.A., Cliff, W.H., Rommens, J.M., Marvin, S.A., Tsui, L-C., Collins, F.S., Frizzell, R.A. and Wilson, J.M. (1990) Cell, 62, 1227-1233.

8. Myers, B.M., Prendergast, F.G., Holman, R., Kuntz, S.M., LaRusso, N.F. (1991) J. Clin. Invest., 88, 1207-1215.

9. Van Dyke, R.W., Matsumoto-Pon, J.K. (1989) Hepatology, 10, 597.

10. Van Dyke, R.W., Ash, K.V. (1990) Hepatology, 11, 896.

11. Ohkuma, S. and Poole, B. (1978) Proc. Natl. Acad. Sci. USA, 75, 3327-3331.

12. Van Dyke, R.W., Hornick, C.A., Belcher, J., Scharschmidt, B.F. and Havel, R.J. (1985) J. Biol. Chem., 260, 11021-11026.

13. Hilden, S.A., Johns, C.A. and Madias, N.E. (1988) Am. J. Physiol., 255, F885F897.

14. Elgavish, A. (1991) Biochem. and Biophys. Res. Comm., 180, 342-348.

15. Bae, H-R. and Verkman, A.S. (1990) Nature, 348, 637-639.

16. Mancini, G.M.S., de Jonge, H.R., Galjaard, H. and Verheijen, F.W. (1989) J. Biol. Chem., 264, 15247-15254.

17. Jonas, A.J. and Jobe, H. (1990) J. Biol. Chem., 265, 17545-17549.

18. Pisoni, R.L. (1991) J. Biol. Chem., 266, 979-985.

19. Barasch, J., Kiss, B., Prince, A., Saiman, L., Gruenert, D. and Al-Awqati, Q. (1991) Nature, 352, 70-73. 